\title{
Prediction of severe acute kidney injury after pediatric cardiac surgery with the use of novel biomarkers: A new trend in clinical research and risk stratification
}

\author{
Petros V. Anagnostopoulos, MD
}

\footnotetext{
From the Division of Pediatric Cardiothoracic Surgery, American Family Children's Hospital, University of Wisconsin Hospital and Clinics, Madison, Wis.

Disclosures: Author has nothing to disclose with regard to commercial support.

Received for publication April 9, 2016; accepted for publication April 12, 2016.

Address for reprints: Petros V. Anagnostopoulos, MD, Division of Pediatric Cardiothoracic Surgery, American Family Children's Hospital, University of Wisconsin Hospital and Clinics, H4/358 Clinical Sciences Center, 600 Highland Ave, Madison, WI 53792 (E-mail: petros@surgery.wisc.edu).

J Thorac Cardiovasc Surg 2016;152:187-8 $0022-5223 / \$ 36.00$

Copyright $(2016$ by The American Association for Thoracic Surgery http://dx.doi.org/10.1016/j.jtcvs.2016.04.033
}

The association of acute kidney injury (AKI) with adverse outcomes increasingly has been recognized. ${ }^{1}$ During the last decade, the diagnosis of AKI was standardized to facilitate classification and research. $^{2,3}$ In 2007 the pediatric risk, injury, failure, loss and end-stage renal disease (pRIFLE) and Acute Kidney Injury Network staging system were described for pediatric and adult patients. . $^{2,3}$

When the pRIFLE criteria were applied to patients after heart surgery, the results were sobering. Up to $56 \%$ of the patients were diagnosed with AKI, which was associated with longer stays in the intensive care unit and hospital and poorer outcomes. ${ }^{4,5}$ Extensive research has been focused on the discovery of the biomarkers of AKI.

Traditionally, renal function was assessed by measuring serum creatinine, urine output, and creatinine clearance (ie, estimated creatinine clearance) ${ }^{1}$; however, serum creatinine increases late after AKI and thus is suboptimal as an early biomarker. Urine output can be influenced greatly by volume status and by the presence of a systemic inflammatory response. An ideal biomarker should be sensitive, easy to measure, reproducible, and inexpensive. Finally, when combined with clinical prediction models, it should potentiate the discrimination of these models. ${ }^{1,6}$

In this issue of the Journal, Cavalcante et $\mathrm{al}^{7}$ measured levels of syndecan-1, a biomarker of endothelial glycocalyx damage and its association with severe AKI in children after open-heart surgery. When levels of syndecan-1 were combined with a clinical prediction model, the discriminatory capacity of the model increased from 0.81 to 0.87 . The addition of renal-specific biomarkers (neutrophil gelatinaseassociated lipocalin) and biomarkers of endothelial cell function (intercellular adhesion molecule 1, e-selectin) did not improve the discrimination of the clinical model.

The study by Cavalcante et $\mathrm{al}^{7}$ is interesting. The primary outcome in this study is severe AKI. In contrast, previous studies did not focus on severe forms of AKI. Up to two-thirds of the patients were classified as pRIFLE-R. It

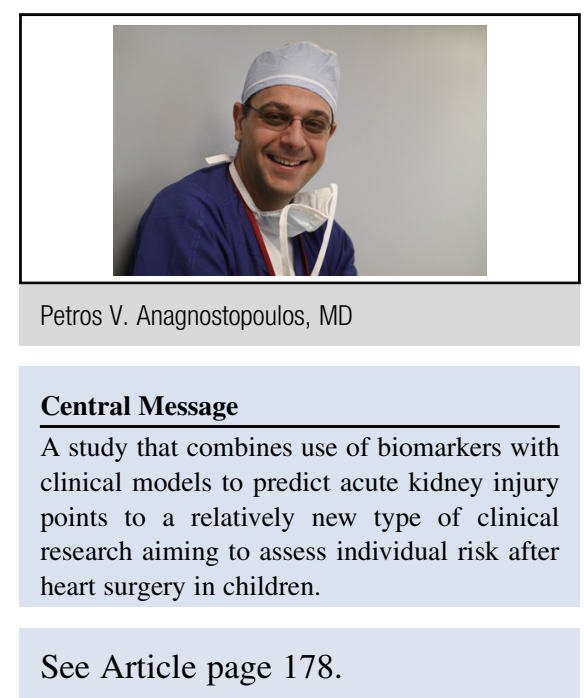

is possible that what was classified as AKI truly represented a small, transient clinically irrelevant decrease in the estimated creatinine clearance. ${ }^{4,5}$ Syndecan- 1 is unique. It peaks early and is cheap, fast, and easy to measure with readily available methods, which makes it an ideal early biomarker of AKI. Potential shortcomings of syndecan-1 as a biomarker include that it is not renal specific and it does not increase preoperatively. The quality of syndecan1 as a predictor of AKI will need to be evaluated in larger, multi-institutional populations.

Nevertheless, studies like the one presented here demonstrate a new type of clinical research. In the past, prospective or retrospective studies focused on describing the associations between various perioperative factors and postoperative outcomes. Application, however, of this knowledge to risk assess individual patients is difficult, if not impossible. Cavalcante et $\mathrm{al}^{7}$ are taking a new approach in combining clinical risk factors with specific biomarkers to generate models and assess individual patient risk. Clinicians need to become more familiar with this research approach. It is very likely that this type of clinical research will become prevalent in the near future and will hopefully produce results that will allow better individual patient specific risk stratification.

\section{References}

1. Schiffl H, Lang SM. Urinary biomarkers and acute kidney injury in children: the long road to clinical application. Pediatr Nephrol. 2013;28:837-42. 
2. Akcan-Arikan A, Zappitelli M, Loftis LL, Washburn KK, Jefferson LS, Goldstein SL. Modified RIFLE criteria in critically ill children with acute kidney injury. Kidney Int. 2007;71:1028-35.

3. Mehta RLKJ, Shah SV, Molitoris BA, Ronco C, Wamock DG, Levin A. Acute Kidney Injury Network: report of an initiative to improve outcomes in acute kidney injury. Critical Care. 2007;11:R31.

4. Ricci Z, Di Nardo M, Iacoella C, Netto R, Picca S, Cogo P. Pediatric RIFLE for acute kidney injury diagnosis and prognosis for children undergoing cardiac surgery: a single-center prospective observational study. Pediatr Cardiol. 2013;34:1404-8.
5. dos Santos El Halal MG, Carvalho PR. Acute kidney injury according to pediatric RIFLE criteria is associated with negative outcomes after heart surgery in children. Pediatr Nephrol. 2013;28:1307-14.

6. Zappitelli M. Preoperative prediction of acute kidney injury — from clinical scores to biomarkers. Pediatr Nephrol. 2013;28:1173-82.

7. de Melo Bezerra Cavalcante CT, Castelo Branco KM, Cavalcante Pinto Júnior V, Cavalcante Meneses G, de Oliveira Neves FM, Gomes de Souza NM, et al. Syndecan-1 improves severe acute kidney injury prediction after pediatric cardiac surgery. J Thorac Cardiovasc Surg. 2016;152:178-86. 